\title{
Caregiver Burden and Social Support in Mothers with $\beta$-Thalassemia Children
}

\author{
Fatemeh Mashayekhi ${ }^{1}$, Rasoul Hashemi Jozdani ${ }^{2}$, Masoumeh Nazari Chamak ${ }^{3} \&$ Sareh Mehni ${ }^{4}$ \\ ${ }^{1}$ Intensive and Critical Care Nursing Lecturer, Faculty Member of Jiroft University of Medical Sciences, Jiroft, \\ Iran \\ ${ }^{2}$ Iran University of Medical Sciences, Tehran, Iran \\ ${ }^{3}$ Medical Educational, Jiroft University of Medical Sciences, Jiroft, Iran \\ ${ }^{4}$ Educational Midwifery Lecturer, Faculty Member of Jiroft University of Medical Sciences, Jiroft, Iran \\ Correspondence: Sareh Mehni, Educational Midwifery Lecturer, Faculty Member of Jiroft University of Medical \\ Sciences, Jiroft, Iran. Tel: 98-91-3148-5248. E-mail: sareh.mehni@yahoo.com
}

Received: February 29, 2016 Accepted: April 14, 2016 Online Published: April 29, 2016

doi:10.5539/gjhs.v8n12p206 URL: http://dx.doi.org/10.5539/gjhs.v8n12p206

\begin{abstract}
Background: In our knowledge, there was no available information on social support and caregiver's burden among parents of thalassemic children.
\end{abstract}

Aim: To examine caregiver's burden and social support in mothers of thalassemic children, this study was conducted.

Methods: This cross-sectional study was conducted from July to October 2013 in Jiroft Thalassemic Center (JTC) in southeast of Iran. To assess the caregiver's burden and social support, caregiver burden scale and Norbeck social support questionnaire was used respectively.

Results: There was a response rate of $98 \%$ (160 out of 163 mothers were participated). Generally, 51.5\% and $49.5 \%$ of mothers reported low and high level of social support, respectively. In term of caregiver's burden, $20 \%$, $29 \%$ and $51 \%$ of mothers reported high, moderate and low level of burden, respectively. There was no significant correlation between mean score of caregiver's burden and mean score of social support.

Conclusion: Our study showed that social support of Iranian mothers with thalassemic children is low. In addition, caregiver's burden among this group of mothers is high. Further research is recommended to prepare more evidence in this regard.

Keywords: caregiver's burden, social support, $\beta$-thalassemia major children, mothers, developing country

\section{Introduction}

B-thalassemia major is a genetic disease which is characterized by defective production of hemoglobin and excessive destruction of red blood cells (Mazzone et al., 2009; Ali et al., 2012) This defect may cause an abnormal development of red blood cells and ultimately anemia with possible presentation of symptom of the thalassemia (Mazzone et al., 2009). Furthermore, $\beta$-thalassemia is a major health problem worldwide and is more prevalent in some parts of Africa, Middle East region, the Indian Sub-continent, South-East Asia, and Melanesia as well as the Pacific Islands (Majid \& Abidi, 2013; Baghianimoghadam et al., 2011). Iran is located on the "Thalassemia Belt" in the Eastern Mediterranean region of World Health Organization (WHO). Iran is indeed one of most important countries with high prevalence of $\beta$-thalassemia major (Ghotbi \& Tsukatani, 2005; Rezaee et al., 2012; Abolghasemi et al., 2007). Although the exact prevalence rates of $\beta$-thalassemia major in Iran are not available; however, it is estimated that prevalence rate of $\beta$-thalassemia major carriers in Iran is about $4 \%$ which is significantly higher than the average $\beta$-thalassemia major gene prevalence $(1.5 \%)$ of world (Miri et al., 2013). Moreover, thalassemia has been spread across Iran, more prevalent in some provinces including Gillan, Mazandaran, Golestan, Bushehr, Hormozgan, Sistan-o-Baluchestan, Khuzestan, Fars and South of Kerman provinces (Gh \& Ghaderi, 2013).

As a chronic disease, $\beta$-thalassemia major has a strong impact on the physical and mental health situation of patients (Nasiri et al., 2014) which could decrease their quality of life (QoL) (Baghianimoghadam et al., 2011; 
Wahyuni et al., 2011). In a case-control study, Wahyuni and colleagues compared QoL of children with $\beta$-thalassemia major with their normal siblings (Wahyuni et al., 2011). They reported that QoL of children with $\beta$-thalassemia major is significantly lower than their normal siblings (Wahyuni et al., 2011). In another study, Ayoub investigated QoL among children with $\beta$-thalassemia major in Western Saudi Arabia with similar results. Ayoub and colleagues also reported that QoL of $\beta$-thalassemia major children could be affected by multiple factors such as family income and a family history of $\beta$-thalassemia major and in turn, $\beta$-thalassemia major could negatively affect parents of $\beta$-thalassemia major patients on their physical, emotional and cognitive levels (Ayoub et al., 2013). In fact, the parents may have severe psychosocial problems due to their inability to cope up with painful situation which leads to worsening of relationship amongst family members, increased marginalization and isolation (Ali et al., 2012). In addition, Sharghi and colleagues reported that prevalence of depression is higher among mothers of $\beta$-thalassemia major children compared to mothers of healthy children (Sharghi et al., 2006). They suggested that screening programs could be designed for decreasing depression burden and promoting QoL of mothers of children with $\beta$-thalassemia major (Sharghi et al., 2006). Finally, Rao and colleagues investigated psychopathology and coping mechanisms in parents of children with $\beta$-thalassemia major in India (Rao et al., 2004). They reported that the rate of psychology problems, especially depression, was high among this group of parents and found out that the use of active coping strategies may be associated with fewer distresses (Rao et al., 2004).

Caregivers of children with $\beta$-thalassemia major are always facing with multiple and extreme challenges to provide high quality care of their patients and, therefore, may experience increased social isolation which in turn could decrease the social support. The social support could affect caregiver's burden in chronic conditions such as $\beta$-thalassemia major. Caregiver burden, by definition, refers to a high level of stress that may be experienced by people who are caring for another person (usually a family member) with some kind of illness. For example, a person caring for someone with a chronic illness may experience such stressors as financial strain, managing the person's symptoms, dealing with crises, the loss of friends, or the loss of intimacy (Mashayekhi et al., 2015). In our knowledge, there was no available information on social support and caregiver's burden among parents of $\beta$-thalassemia major children. The aim of present study was to examine caregiver's burden and social support in mothers of $\beta$-thalassemia major children in southeast of Iran.

\section{Materials and Methods}

\subsection{Design, Setting and Ethical Considerations}

This cross-sectional study was conducted from July to October 2013 in Jiroft Thalassemic Center (JTC) in southeast of Iran. The project was approved by both Jiroft University of Medical Science and JTC. All mothers of major $\beta$-thalassaemic children who were attending to the JTC in the period were enrolled. Written consent was obtained from each participant. The research was comprehensively described to each participant, and she was assured that her information would only be used for research purposes and would be completely confidential.

\subsection{Instruments}

A questionnaire was designed to obtain background information on social support and caregiver's burden which was answered by participants themselves. Caregiver burden was assessed with the caregiver burden scale (Elmståhl et al., 1996). The questionnaire had 22 questions concerning burden of different aspects on the caregiver's health, feeling of psychological well-being, relations, social network, and physical workload as well as potential important environmental aspects. When the scale was developed, factor analysis was used to yield 5 indices-general strain (8 questions), disappointment (5 questions), isolation (3 questions), emotional involvement (3 questions) and environment (3 questions). Responses were scored on a scale from 1 to 4 (not at all, seldom, sometimes, and often). The total burden index was the mean of all 22 items. Higher scores indicated greater burden. The total burden index was divided into three groups: low burden (1.00-1.99), medium burden (2.00-2.99) and high burden (3.00-4.00) (Mashayekhi et al., 2014). For measuring mother's perceived social support, the self-administrated Norbeck social support questionnaire was used. This questionnaire measured three functional types of social support: affect, affirmation, and aid (Norbeck et al., 1983). Validity and reliability of both caregiver burden scale and Norbeck social support questionnaire were determined in good level in Iranian context in previous studies.

\subsection{Statistical Analysis}

The data was analyzed using the Statistical Package for the Social Sciences (SPSS) 21. Descriptive statistics and were used for the continuous variables. Pearson correlation is used to show the relationship between caregiver burdens and demographic variables and multivariate regression is used to show the effect of demographic factors on caregiver burden and social support. The significance level was considered below $0.005(\mathrm{p}<0.005)$. 


\section{Results}

There was a response rate of $98 \%$ (160 out of 163 mothers were participated). The mean age of participants was $38.1 \pm 9.3$ years (range between 17 to 60 years). The mean age of $\beta$-thalassemia major children was $10.7 \pm 4.8$ years. Table 1 shows the demographic information of participants.

Table 1. Participant's demographics information

\begin{tabular}{llll}
\hline & & Numbers & Percent \\
\hline \multirow{2}{*}{ Marital status } & Married & 144 & $\mathbf{9 0}$ \\
& Widowed, divorced & 16 & $\mathbf{1 0}$ \\
Level of education & High school & 120 & $\mathbf{7 5}$ \\
& Diploma & 34 & $\mathbf{2 1 . 3}$ \\
Level of income & Post diploma & 6 & $\mathbf{3 . 7}$ \\
& good & 18 & $\mathbf{1 1 . 2}$ \\
Use of governmental helps & poor & 142 & $\mathbf{8 8 . 8}$ \\
\multirow{3}{*}{ Living alone } & yes & 14 & $\mathbf{8 . 8}$ \\
& no & 146 & $\mathbf{9 1 / 2}$ \\
& yes & 97 & $\mathbf{6 0 . 6}$ \\
\hline
\end{tabular}

Mean score of social support reported by mothers were $33.8 \pm 16.3$. Generally, $51.5 \%$ and $49.5 \%$ of mothers reported low and high level of social support, respectively. The mother's low level of income and living alone could significantly affect their social support.

In term of caregiver's burden, $20 \%, 29 \%$ and $51 \%$ of mothers reported high, moderate and low level of burden, respectively. Mean score of burden reported by mothers was $43.9 \pm 16.2$. The items on the caregiver's burden were divided into five indexes: general strain, isolation, disappointment, emotional involvement and environment. While the highest value was belonged to general strain (mean score 15.3 \pm 6.7 ), the lowest value was belonged to isolation (mean score 5.56 \pm 2.68 ) (Table 2).

Table 2. Mean score of caregiver's burden items

\begin{tabular}{ll}
\hline items & Mean \\
\hline General strain & $\mathbf{1 5 . 3 1} \pm 6.79$ \\
Isolation & $\mathbf{5 . 5 6} \pm \mathbf{2 . 6 8}$ \\
Disappointment & $\mathbf{1 1 . 6 3} \pm \mathbf{4 . 3 6}$ \\
Emotional involvement & $\mathbf{5 . 0 3} \pm \mathbf{2 . 4 7}$ \\
Environment & $\mathbf{6 . 5 2} \pm \mathbf{2 . 4 7}$ \\
Total score of caregiver burden & $\mathbf{4 3 . 9 0} \pm \mathbf{1 6 . 2 9}$ \\
\hline
\end{tabular}

There was a positive and significant correlation between mean score of caregiver's burden and mothers' age as well as a negative and significant correlation between mean score of caregiver's burden and mothers' level of income. However, there was no significant correlation between mean score of caregiver's burden and mean score of social support (Table 3). 
Table 3. Correlation and relationship between demographics characteristics with caregiver's burdens and social support

\begin{tabular}{|c|c|c|c|c|c|c|c|c|c|c|c|c|c|c|c|c|}
\hline & & 1 & 2 & 3 & 4 & 5 & 6 & 7 & 8 & 9 & 10 & 11 & 12 & 13 & 14 & 15 \\
\hline 1 & Age of children & 1 & & & & & & & & & & & & & & \\
\hline 2 & Child gender & 0.022 & 1 & & & & & & & & & & & & & \\
\hline 4 & Marital status & $0.160 *$ & $0.021 *$ & $0.317^{*}$ & 1 & & & & & & & & & & & \\
\hline 5 & Only careful & -0.145 & -0.037 & -0.115 & -0.141 & 1 & & & & & & & & & & \\
\hline 8 & $\begin{array}{l}\text { government } \\
\text { institutions }\end{array}$ & -0.094 & 0.104 & 0.036 & -0.044 & 0.023 & 0.043 & $0.180^{*}$ & 1 & & & & & & & \\
\hline 9 & $\begin{array}{l}\text { Caring for } \\
\text { someone }\end{array}$ & -0.037 & -0.124 & -0.062 & -0.032 & $0.166^{* *}$ & 0.061 & $0.158^{*}$ & 0.011 & 1 & & & & & & \\
\hline 13 & Isolation & 0.005 & -0.029 & 0.130 & -0.063 & -0.014 & -0.054 & $-0.172 *$ & 0.107 & 0.120 & -0.040 & $0.818^{* *}$ & $0.692 * *$ & 1 & & \\
\hline 14 & Disappointment & 0.089 & -0.081 & $0.160^{*}$ & 0.057 & 0.023 & -0.129 & -0.107 & 0.045 & 0.033 & 0.087 & $0.861 * *$ & $0.716^{* *}$ & $0.631^{* *}$ & 1 & \\
\hline 15 & $\begin{array}{l}\text { Emotional } \\
\text { involvement }\end{array}$ & 0.143 & 0.052 & 0.114 & -0.013 & -0.103 & $-0.227 * *$ & $-0.202^{*}$ & 0.031 & -0.020 & 0.057 & $0.760 * *$ & $0.660 * *$ & $0.592 * *$ & $0.596^{* *}$ & 1 \\
\hline 16 & Environment & 0.075 & -0.087 & $0.168^{*}$ & 0.056 & -0.011 & -0.115 & -0.049 & 0.030 & 0.036 & 0.038 & $0.809 * *$ & $0.717 * *$ & $0.653 * *$ & $0.637 * *$ & $0.511 * *$ \\
\hline
\end{tabular}

Multivariate linear regression results indicates that maternal age is the most important factor affecting caregiver burden which determines the dependent variables changes. (Table 4)

Table 4. Multivariate linear regression results of the factors influencing caregiver burden and its components

\begin{tabular}{llllll}
\hline Dependent variable & Independent variable & $\boldsymbol{\beta}$ & $\mathbf{R 2}$ & $\mathbf{P}$ & $\mathbf{F}$ \\
\hline Caregiver burden & Mothers' age & 0.338 & 0.2 & 0.01 & $\mathbf{6 . 1}$ \\
General strain & Mothers' age & 0.142 & 0.273 & 0.002 & $\mathbf{6 . 3 3}$ \\
Disappointment & Income & 3.42 & 0.273 & 0.002 & $\mathbf{6 . 3 3}$ \\
Emotional involvement & Mothers' age & 0.75 & 0.16 & 0.043 & $\mathbf{6 . 1 7}$ \\
Environment & Mothers' age & -1.059 & 0.227 & 0.004 & $\mathbf{8 . 6}$ \\
\hline
\end{tabular}

\section{Discussion}

To examine caregiver's burden and social support in mothers of major $\beta$-thalassemic children, this study was conducted. The results showed that $51.5 \%$ of mothers of major $\beta$-thalassemic children have low level of social support. We also found that prevalence of caregiver's burden is high among this group of mothers.

The Iranian population consists of several ethnic groups, mostly "Aryan origin" (Rezaee et al., 2012). Among the eastern Mediterranean countries, Iran is one of the countries with high prevalence of thalassemia (Ghotbi \& Tsukatani, 2005; Rezaee et al., 2012; Miri-Moghaddam et al., 2014; Samavat \& Modell, 2004). It is estimated that annually about 1,000 thalassemia major patients are adding to current patients in Iran; there are more than 25,000 patients in Iran which have to receive blood regularly (Ghotbi \& Tsukatani, 2005; Gh \& Ghaderi, 2013). During two recent decades, Iranian health care agencies have conducted many efforts to decrease the prevalence of thalassemia among Iranian population. The first national (Iranian) program for control of thalassemia was 
started in 1996 to create a general infrastructure for prevention of genetic disorders (Gh \& Ghaderi, 2013; Samavat \& Modell, 2004). Screening was included as part of existing mandatory premarital blood tests. Initially, couples at risk were offered only information and genetic counseling, because abortion after prenatal diagnosis is not allowed in Iran. The second strategy was established in 2001. Based on this strategy, patients' families were identified and consultation services were provided for them. If they had not had any healthy children, they were referred to prenatal diagnosis centers to have healthy children; consequently, genetic testing and prenatal care were developed in Iran. This has led to a dramatic reduction in new cases of $\beta$-thalassemia major. The third strategy was started in provinces with high prevalence rates in 2005 (Gh \& Ghaderi, 2013).

Although national programs for control of $\beta$-thalassemia major resulted in a decreased rate of thalassemia in Iran, but it seems that social support and caregivers burden of parent of children with $\beta$-thalassemia major remains an important problem. Due to traditional beliefs, religious beliefs, cultural and socio-demographic characteristics in Iranian population, responsibilities of caring of children with chronic disease such as major $\beta$-thalassemia children are usually with their mothers. Mothers of thalassemic children usually have to tolerate an extra care and support for their children's needs which in turn would markedly increase the risk of caregiver's burden (Sharghi et al., 2006). The available research on problems of family members of children with thalassemia is very limited. In 2007, Yazdi and colleagues investigated psychosocial, social and financial problems with coping strategies among Iranian family members of thalassemic children (Kh, 2007). They reported that in all three dimensions, parents of thalassemic children experienced many problems. They also found that believing in God and life after death is most coping strategies that was used by parents to challenge with their situation (Yazdi kh, 2007) In fact, low social support and high prevalence of caregiver's burden among parents of as major $\beta$-thalassemia children may affect their QoL. In another study, Zarea examined QoL of Iranian parents with as major $\beta$-thalassemia children and reported that as major $\beta$-thalassemia as a chronic disease poses challenges to patients and family members at the individual, social and psychological levels and decreased their QoL significantly (Zarea K et al., 2012).

\section{Conclusion}

To our knowledge this is the first study which examined social support and caregivers' burden among mothers of children with as major $\beta$-thalassemia. Our study showed that social support of Iranian mothers with as major $\beta$-thalassemia children is low. In addition, caregiver's burden among this group of mothers is high. However, we did not found any relationship between social support and caregiver's burden of parents of as major $\beta$-thalassemia children. Further research is recommended to prepare more evidence in this regard.

\section{Limitation}

This study was based on a convenience sample and participation was voluntary; therefore, there might have been a selection bias which may effect on the possibility of generalizing the results to all parents of as major $\beta$-thalassemia children. Furthermore, use of the self-report questionnaires, may have led to an overestimation of some of the findings due to variance, which is common in different methods.

\section{Acknowledgments}

Researchers of the University of Jiroft Medical Sciences do appreciate the research assistants for their financial support of this research project. They also thank mothers and children with Thalassemia who participated in the research and helped us in conducting this study.

\section{Competing Interests Statement}

The authors declare that there is no conflict of interests regarding the publication of this paper.

\section{References}

Abolghasemi, H., Amid, A., Zeinali, S., Radfar, M. H., Eshghi, P., Rahiminejad, M. S., ... Afrasiabi, A. (2007). Thalassemia in Iran: Epidemiology, prevention, and management. Journal of Pediatric Hematology/Oncology, 29, 233-238. http://dx.doi.org/10.1097/MPH.0b013e3180437e02

Ali, S., Sabih, F., Jehan, S., Anwar, M., \& Javed, S. (2012). Psychological distress and coping strategies among parents of beta-thalassemia major patients. International Conference on Clean and Green Energy, 124-128.

Ayoub, M. D., Radi, S. A., Azab, A. M., Abulaban, A. A., Balkhoyor, A. H., Seif-Eleslam, W. B., ... Kari, J. A. (2013). Quality of life among children with beta-thalassemia major treated in Western Saudi Arabia. Saudi Medical Journal, 34, 1281-1286.

Baghianimoghadam, M. H., Sharifirad, G., Rahaei, Z., Baghianimoghadam, B., \& Heshmati, H. (2011). Health related quality of life in children with thalassaemia assessed on the basis of SF-20 questionnaire in Yazd, 
Iran: A case-control study. Central European Journal of Public Health, 19, 165.

Elmståhl, S., Malmberg, B., \& Annerstedt, L. (1996). Caregiver's burden of patients 3 years after stroke assessed by a novel caregiver burden scale. Archives of Physical Medicine and Rehabilitation, 77, 177-182. http://dx.doi.org/10.1016/S0003-9993(96)90164-1

Gh, M., \& Ghaderi, E. (2013). Chronic disease program in Iran: Thalassemia control program. Chron Dis J, 1, $1-9$.

Ghotbi, N., \& Tsukatani, T. (2005). Evaluation of the national health policy of thalassaemia screening in the Islamic Republic of Iran.

Kh, Y. (2007). Psychosocial, social and financial problems with coping strategies among families with thalassemic patients. Journal of Gorgan University of Medical Sciences, 9, 71-75.

Majid, S., \& Abidi, M. (2013). Quality of Life and Coping Styles of Care-Givers of Patients Suffering From Thalassemia Major. International Journal of Medical and Pharmaceutical Sciences, 3, 41-48.

Mashayekhi, F., Pilevarzadeh, M., \& Rafati, F. (2015). The Assessment of Caregiver Burden in Caregivers of Hemodialysis Patients. Materia Socio-Medica, 27, 333. http://dx.doi.org/10.5455/msm.2015.27.333-336

Mashayekhi, F., Rafati, S., Rafati, F., Pilehvarzadeh, M., \& Mohammadi-Sardo, M. (2014). A study of caregiver burden in mothers with thalassemia children in Jiroft, 2013. Modern Care Journal, 11, 229-235.

Mazzone, L., Battaglia, L., Andreozzi, F., Romeo, M. A., \& Mazzone, D. (2009). Emotional impact in $\beta$-thalassaemia major children following cognitive-behavioural family therapy and quality of life of caregiving mothers. Clinical Practice and Epidemiology in Mental Health, 5, 5. http://dx.doi.org/10.1186/ 1745-0179-5-5

Miri, M., Tabrizi Namini, M., Hadipour Dehshal, M., Sadeghian Varnosfaderani, F., Ahmadvand, A., Yousefi Darestani, S., \& Manshadi, M. (2013). Thalassemia in Iran in last twenty years: The carrier rates and the births trend. Iranian Journal of Blood and Cancer, 6, 11-17.

Miri-Moghaddam, E., Motaharitabar, E., Erfannia, L., Dashipour, A., \& Houshvar, M. (2014). High school knowledge and attitudes towards thalassemia in southeastern Iran. International Journal of Hematology-Oncology and Stem Cell Research, 8, 24.

Nasiri, M., Hosseini, H., \& Shahmohammadi, S. (2014). Mental health status in patients with Thalassemia major in Iran. Journal of Pediatrics Review, 2, 55-61.

Norbeck, J. S., Lindsey, A. M., \& Carrieri, V. L. (1983). Further development of the Norbeck Social Support Questionnaire: Normative data and validity testing. Nursing research, 32, 4-9. http://dx.doi.org/10.1097/ 00006199-198301000-00002

Rao, P., Pradhan, P. V., \& Shah, H. (2004). Psychopathology and coping in parents of chronically ill children. The Indian Journal of Pediatrics, 71, 695-699. http://dx.doi.org/10.1007/BF02730656

Rezaee, A. R., Banoei, M. M., Khalili, E., \& Houshmand, M. (2012). Beta-Thalassemia in Iran: New insight into the role of genetic admixture and migration. The Scientific World Journal. http://dx.doi.org/10. $1100 / 2012 / 635183$

Samavat, A., \& Modell, B. (2004). Iranian national thalassaemia screening programme. Bmj, 329, 1134-1137. http://dx.doi.org/10.1136/bmj.329.7475.1134

Sharghi, A., Karbakhsh, M., Nabaei, B., Meysamie, A., \& Farrokhi, A. (2006). Depression in mothers of children with thalassemia or blood malignancies: A study from Iran. Clinical Practice and Epidemiology in Mental Health, 2, 27. http://dx.doi.org/10.1186/1745-0179-2-27

Wahyuni, M. S., Ali, M., Rosdiana, N., \& Lubis, B. (2011). Quality of life assessment of children with thalassemia. Paediatr Indone, 51, 163-169.

Yazdi, K. (2007). Psychosocial, social and financial problems with coping strategies among families with thalassemic patients. Journal of Gorgan University of Medical Sciences, 9, 71-75.

Zarea, K., Baraz Pordanjani, S., Pedram, M., \& Z, P. (2012). Quality of life in children with thalassemia who referred to thalassemia center of Shafa Hospital. Jundishapur Journal of Chronic Disease Care, 1, 45-53. 


\section{Copyrights}

Copyright for this article is retained by the author(s), with first publication rights granted to the journal.

This is an open-access article distributed under the terms and conditions of the Creative Commons Attribution license (http://creativecommons.org/licenses/by/3.0/). 